also to direct their investigations towards problems of the disease as it affects children.

\section{Conclusion}

It is realized that centralization makes visiting of children in hospital and out-patient attendance somewhat difficult, and for this reason a case can be made for treating children with leukaemia near their homes. But the initial treatment of those with non-leukaemic tumours rarely lasts more than six weeks, and follow-up need not be very frequent. Everyone realizes that these children are suffering from a desperate disease, and there must be few parents who would not put up with a reasonable amount of inconvenience so long as they believed that their children were getting good treatment ; also, this inconvenience could be reduced to a minimum by the provision of accommodation for parents in hospital. It is much easier to collect patients together if they live in a densely populated area. For example, if one centre were set up for the treatment of children with tumours from the Metropolitan regions an enormous contribution could be made.

One thing must be accepted. Children's cancer research is a joint responsibility of paediatricians, radiotherapists, surgeons, and pathologists. If the treatment of children's tumours were reorganized new methods could be efficiently assessed and advantage be taken of the great research potential that is available.

\section{Summary}

Each year 100 children in the Manchester Hospital Region develop tumours, and $70 \%$ of these patients die. It is likely that a significant improvement in the survival rate will come only when adjuvant treatment-for example, chemotherapyis used to supplement surgery and $x$ rays. The fact that children with tumours are treated in so many different hospitals hinders the assessment of new techniques and research. It is suggested that these patients are best treated in centres each serving a population of at least one and a half million children.

This work could not have been carried out without the ready co-operation of the clinicians and pathologists of the Manchester Region. The organization for treating children with tumours has been criticized in this article. It is hoped that nobody will interpret this as a criticism of any individual-such is certainly not my intention.

The Registrar-General kindly furnished data about the incidence of malignant tumours in the various hospital regions during 1961. Thanks are also due to Professor Wilfrid Gaisford, Professor A. C. P. Campbell, and Dr. Eric Easson for their help and encouragement, and to Mrs. N. Rowe for secretarial assistance.

Part of the cost of this survey was defrayed by grants from the British Empire Cancer Campaign.

\section{REFERENCES}

Aitken-Swan, J., and Paterson, R. (1959). Brit. med. F., 1, 708. Burchenal, J. H., Murphy, M. L., Ellison, R. R., Sykes, M. P., Tan, T. C., Leone, L. A., Karnofsky, D. A., Craver,

H. W., and Rhoads, C. P. (1953). Blood, 8, 965 . 1961). Brit. med. ₹., 1, 448.

Farber, S. (1949). Blood, 4, 160

Pearson, O. H., and Eliel, L. P. (1950). F. Amer. med. Ass., 144, 1349

Pearson, 1961 registered under the National Cancer Registration Scheme (unpublished data).

Tivey, H. (1952). Pediatrics. 10, 48.

\title{
Review of Regional Limb Perfusion with Melphalan for Malignant Melanoma*
}

\author{
W. T. IRVINE, $\dagger$ M.D., CH.M., B.SC., F.R.C.S. ; R. J. LUCK, $\ddagger$ M.B., F.R.C.S.
}

Malignant melanoma, though often diagnosed at an early stage in its natural history, has a high mortality. Pack et al. (1952) reviewed over 1,000 cases and found that only $21.4 \%$ were free of disease after five years. The prognosis is much better when the regional lymph nodes are not involved, and Block and Hartwell (1961) reported a $50 \%$ five-year survival rate in the absence of involved regional nodes. Ackerman and del Regato (1954) reported a $30 \%$ five-year survival in the absence of node involvement, $15 \%$ survival with histological involvement, and $5 \%$ survival when the nodes are clinically affected.

It is characteristic of many melanomata that multiple cutaneous and subcutaneous metastases may be present in the limb between the primary tumours and the nodes draining the involved region. Removal of the primary lesion combined with block-dissection of the regional nodes consequently leaves an area of tissue between, which may contain viable malignant cells. Excision of the primary, together with the skin and sub-

\footnotetext{
- From the Surgical Units of St. Mary's Hospital and the London Hospital.

† Professor of Surgery, St. Mary's Hospital, London.

‡ Lecturer in Surgery, St. Mary's Hospital, London.
}

cutaneous tissues in continuity with the regional lymph nodes, is therefore advised when practicable, as in the upper arm and upper leg. However, lesions below the knee and elbow are of ten associated with lymphatic spread along the deep vessels, and controversy exists about the place of prophylactic blockdissection of the regional nodes. Stehlin (1963) suggested that the lymphoedema which often follows block-dissection encourages the spread and growth of subcutaneous metastases, and Petersen et al. (1962) also found that skin metastases are more frequent when prophylactic block-dissection is carried out at the same time as excision of the primary. It is also argued that removal of the glands removes a filter against metastases in the lymphatic channels.

These opinions are supported by Vogler et al. (1958) and Sandeman (1965); on the other hand, prophylactic blockdissection has the theoretical advantage that it provides a greater chance of cure for patients in whom there is microscopical involvement of the nodes, and the procedure is advocated by Charalambidis and Patterson (1962), Meyer and Gumport (1953), and Southwick et al. (1962). Peterson et al. (1962) found it beneficial only if delayed for two to three weeks after 
removal of the primary. In McNeer's (1965) experience there is no benefit from deferment of regional lymph-node excision in cases of distal limb melanoma. He found that $23 \%$ of 335 patients with clinically negative nodes had histological involvement of these nodes. In his series the five-year survival rate free of disease in patients with microscopic metastases in the lymph nodes was $53 \%$, against $10 \%$ when the nodes were obviously involved clinically. This is in keeping with our own experience, and we prefer lymph-node excision in continuity with the tumour for lesions of the proximal arm and leg. For lesions below the knee and elbow in which microscopic metastases may lie deeply outside the scope of surgical excision regional perfusion with a cytotoxic drug is a possible answer to the problem of the potential local recurrence in the area between the primary tumour and the regional nodes, and, if shown to be effective, it would largely nullify the arguments against prophylactic block-dissection.

Treatment of multiple local recurrences by standard methods is unsatisfactory. Treidman and McNeer (1963) reported that a solitary recurrence within $5 \mathrm{~cm}$. of the area of primary surgery was associated with $44 \%$ five-year survival, but at greater distances or when multiple recurrences occur the five-year figure falls to below $16 \%$. Many of the cases reported here are from this bad-prognosis group.

The technique of regional perfusion is a development by Creech et al. (1958) of the work of Klopp et al. (1950), who attempted to obtain high local concentration of cytotoxic drugs by an intra-arterial injection. By regional perfusion of a limb we can safely administer a dose of drug which would be lethal if given systemically. With the limb circulation isolated from the body, the limiting factor to dosage is the sensitivity of the normal tissues of the limb to damage by the drug; the complications of bone-marrow aplasia, intestinal necrosis, sterility, and alopecia can be avoided.

\section{Method}

Twenty-nine patients have undergone 33 regional limb perfusions with melphalan ( $\mathrm{L}$-phenylalanine nitrogen mustard; Alkeran) (Bergel and Stock, 1953) for malignant melanoma. The operative technique used is that described by Irvine et al. 11962). The average age was 44 years ; 22 patients were female. Thirty of the 33 perfusions were of the leg, and 14 of these were by the common femoral artery, the remainder by the external iliac vessels. The three arm perfusions were via the axillary artery. In 17 cases block-dissection was carried out at the time of perfusion. Difficulties in technique were not commonly encountered, though in repeat perfusions and in those following a block-dissection complicated by infection scar tissue involving the femoral vessels made the procedure more difficult. It was necessary in two iliac perfusions, for technical reasons, to obtain the venous return from the femoral vein. A tourniquet was used in all but two perfusions, of which one was a high axillary perfusion and the other an external iliac perfusion. The melphalan was prepared by dissolving it in acid alcohol. In twi patients, not included here, a water-soluble ester hydrochloride was used and caused extensive tissue necrosis (Irvine et al., 1962. The dose varied from 1 to $2 \mathrm{mg}$. $/ \mathrm{kg}$., and the largest absolute dose was $145 \mathrm{mg}$. in a $97 \mathrm{~kg}$. man. The flow rate of the perfusion varied from 100 to $350 \mathrm{ml} . / \mathrm{min}$. and the duration ranged from 40 to .05 minutes. The limb circulation was washed out with saline at the end of the perfusion.

The leakage of drug into the systemic circulations of the patient was initially measured by injecting $20 \mathrm{ml}$. of a ${ }^{51} \mathrm{Cr}$ labelled red-cell suspension into the input side of the pump. At 30 and 60 minutes amples of blood were taken from the patient; by comparing the radioactive concentration of the injected red-cell suspension and the peripheral blood and relating this to the patient's b!ood volume (estimated from height and weight tables) the degrie of leakage could be calculated. Because of the inconvenience of obtaining and labelling suitable red-blood cells, ${ }^{13}{ }^{1} \mathrm{I}$-labelled albumin replaced ${ }^{51} \mathrm{Cr}$-labelled. In some cases where the leak was measured by both ${ }^{51} \mathrm{Cr}$-labelled red cells and ${ }^{13} 1$ I-labelled albumin similar results were obtained. More recently ${ }^{125} \mathrm{I}$ has been shown to have many advantages over ${ }^{13} 1$ I (Hobbs and Edwards, 1962), and in the latest cases ${ }^{125} \mathrm{I}$-labelled human serum albumin was used to estimate the leak. These methods do not necessarily represent the leak of cytotoxic drug but indicate the extent of mixing between the systemic circulation and the circulation of the perfused limb. Ideally the radioactive label should be attached to the drug used.

In three patients bone-marrow was aspirated immediately before perfusion and replaced 12 to 24 hours post-operatively. (The half-life of melphalan in blood at $37^{\circ} \mathrm{C}$. is between 105 and 120 minutes.)

\section{Results}

The patients were analysed in three groups.

\section{Group I}

This group consisted of 11 patients in whom regional perfusion was part of the primary treatment. In 10 of these cases the perfusion was done at the time of, or within 9 weeks of, excision of the primary tumour (the delays resulted because the primary surgery was carried out at other hospitals); in the eleventh case there was a delay of one year between removal of the primary tumour and perfusion, but there was no recurrence or evidence of spread at the time of perfusion. In all but one of this group block-dissection of the regional glands was performed at the time of perfusion; the single exception was an old man whose melanoma of a great toe was treated by local amputation and femoral perfusion only.

The results are shown in Table $I$. Of the 11 patients in this group nine were free from disease after an average followup of 23 months. Two of the 11 patients had histological involvement of the regional nodes, and a third had clinically obvious node enlargement. Only one patient has died, death occurring two and a half years after perfusion. No blockdissection was carried out on this patient ; necropsy showed an anaplastic retroperitoneal tumour. The patient who had clinically involved lymph nodes developed a lung metastasis after a second perfusion of the leg.

Table I.-Eleven Patients who Underwent Regional Perfusion as Part of

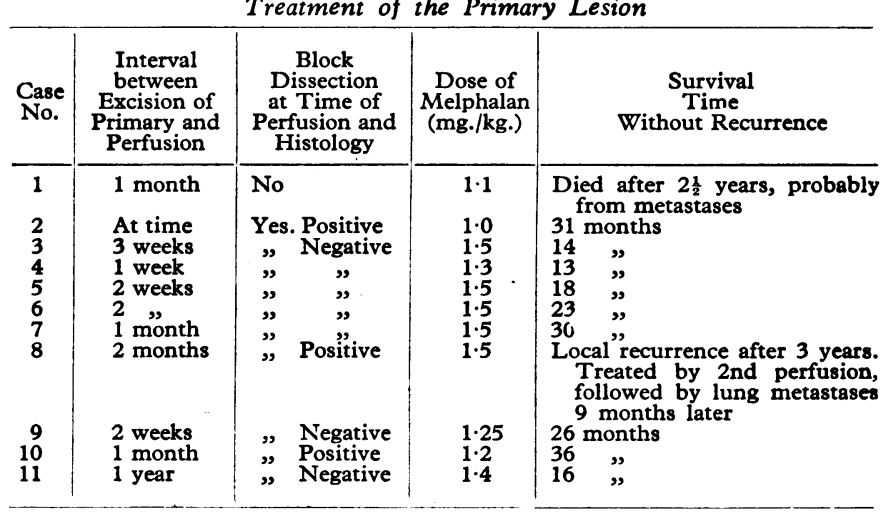

\section{Group II}

This group is composed of 16 patients who had regional perfusions for the treatment of recurrences. A subdivision has been made into: (a) those who had the recurrence(s) removed surgically before or with the perfusion (six patients), and (b) those whose local recurrence was left so that the effect of the cytotoxic drug could be assessed (10 patients-13 perfusions). 
The results of group 2 are shown in Tables II and III. Of the six patients whose recurrent lesion was removed before or with perfusion three were free from disease after an average follow-up of 32 months. One has required a through-hip amputation because of further recurrences, another has generalized spread, and a third has died. The latter two had histologically positive nodes. The patients in Table III illustrate how effective melphalan can be in this disease ; of the 13 perfusions four produced complete regression and a further four partial regression of the recurrence(s). However, the complete regressions have all been temporary. Figs. 1-4 illustrate clinical and histological effectiveness of melphalan perfusion.

\section{Group III}

This group is composed of three patients in whom the disease was advanced and perfusion was palliative. Table IV shows that the treatment was quite ineffective in relieving the local condition or in prolonging life.

\section{Complications of Regional Perfusion}

There were no deaths due to operation or to toxic effects of melphalan. There was, however, a definite morbidity.

Leucopenia and Anaemia.-Two patients had a leucopenia below 1,000/c.mm., and the white-cell counts of these patients are shown in Fig. 5. Both were treated by isolation and anti-

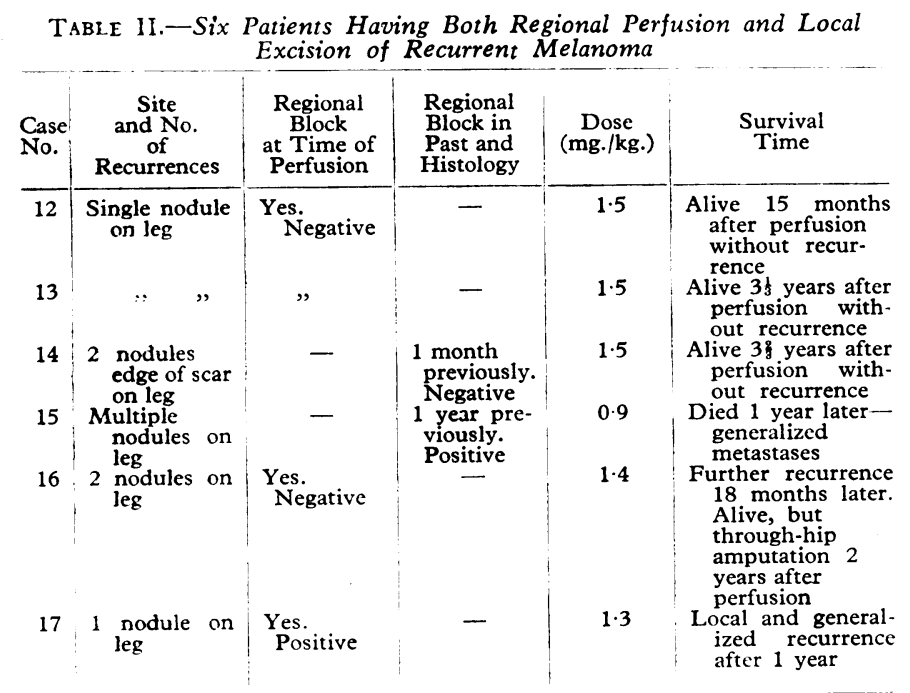

biotics, and recovered without further incident. In seven patients the W.B.C. fell to below $2,000 / \mathrm{c} . \mathrm{mm}$. The average time for maximum fall in W.B.C. was 13 days. There was poor correlation between measured leak of drug into systemic circulation and the subsequent depression of W.B.C. ; for example, the patient whose leucocyte count fell to 700 had only a $20 \%$ leak, and had a "wash-out" of the limb-circulation with 2 litres of saline before the tourniquet was released; while in two other patients with leaks of $70 \%$ and $65 \%$ the W.B.C. fell no lower than 4,000 and $3,000 / \mathrm{c} . \mathrm{mm}$. respectively. It is interesting that the patient whose count fell to 400 (Fig. 5) had marrow removed, stored, and reinfused apparently without effect.

Anaemia to below $10 \mathrm{~g}$. $\mathrm{Hb} / 100 \mathrm{ml}$. occurred in nine patients. The lowest platelet count in the entire series was 120,000 , and there were no bleeding problems in any case.

Skin Damagc.-Skin necrosis occurred in one patient in the present series, and in this case there was almost complete loss of skin of the thigh, extensive grafting being required; the calf and foot were unaffected. In one arm-perfusion blistering and desquamation of the skin occurred, but in the remainder of the cases nothing more than erythema was seen. Skin grafts had been applied in two patients 50 and 18 days before perfusion respectively, but the perfusion did not damage the grafts in any way.

Peripheral Neuritis.-This occurred in two of three armperfusions. In both, pain and weakness persisted for two to three months before complete recovery ensued.

Gastro-intestinal Symptoms.-Vomiting during the first 24 post-operative hours was common, but in only one case did this continue and become a serious problem; this man eventually had a haematemesis on the seventh day and then recovered slowly.

Vascular Complications.-There was one case of arterial occlusion. This was diagnosed on the day after operation; the groin was explored and a soft clot sucked out of the femoral artery, with restoration of pulses. This patient subsequently underwent two further perfusions through the femoral artery. Venous occlusion occurred at the site of perfusion in three patients. This happened immediately after operation in one,

TABle IV.-Three Patients in whom Regional Perfusion was Performed

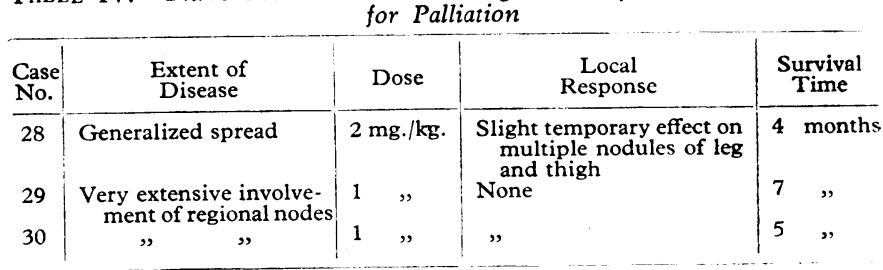

TABLE III.-10 Patients in whom Recurrence was Treated by Perfusion without Local Excision

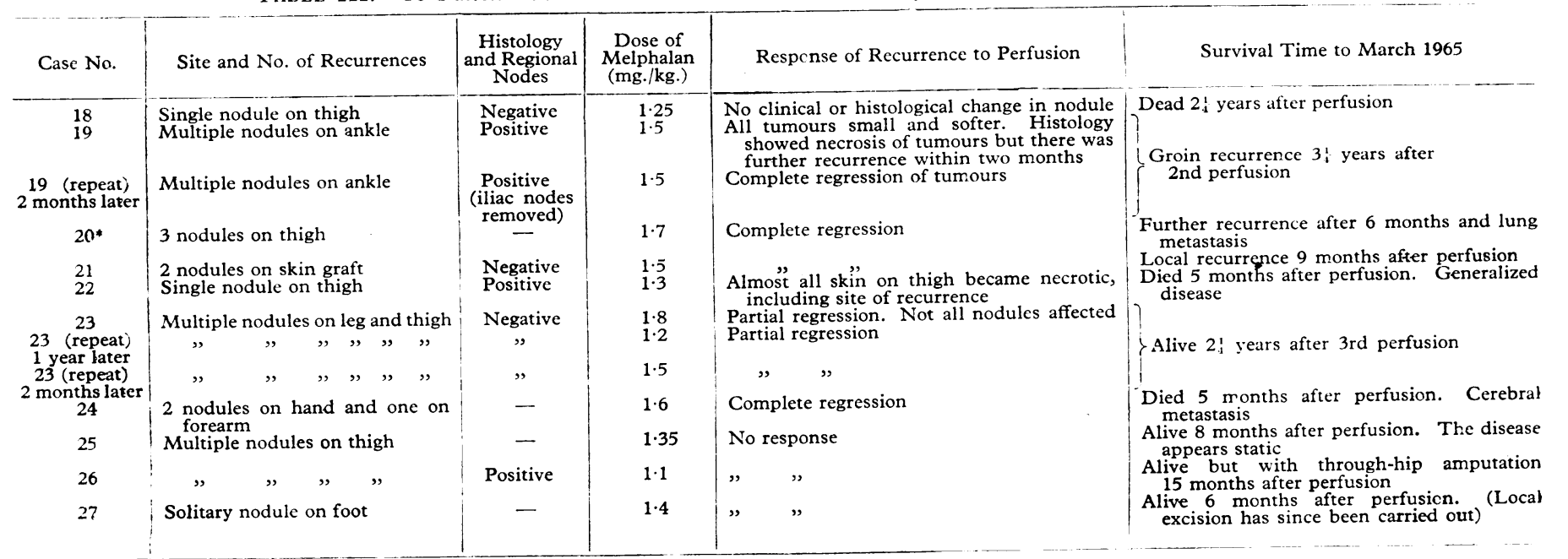

- This patient also appears in Table $\mathrm{I}$ (Case 8 ) because of a previous perfusion for the primary. 
on the sixth day in another, and in the third patient the vein was found to be thrombosed when another perfusion was undertaken.

Lymphoedema.-This was the most common complication, but it is more closely related to node-dissection than to perfusion. Three patients who had perfusion without blockdissection had no oedema. Table $\mathrm{V}$ shows the incidence of lymphoedema in relation to block-dissection and perfusion.

Delay in Wound-healing.-There was no definite evidence that perfusion resulted in delayed healing. The average stay in
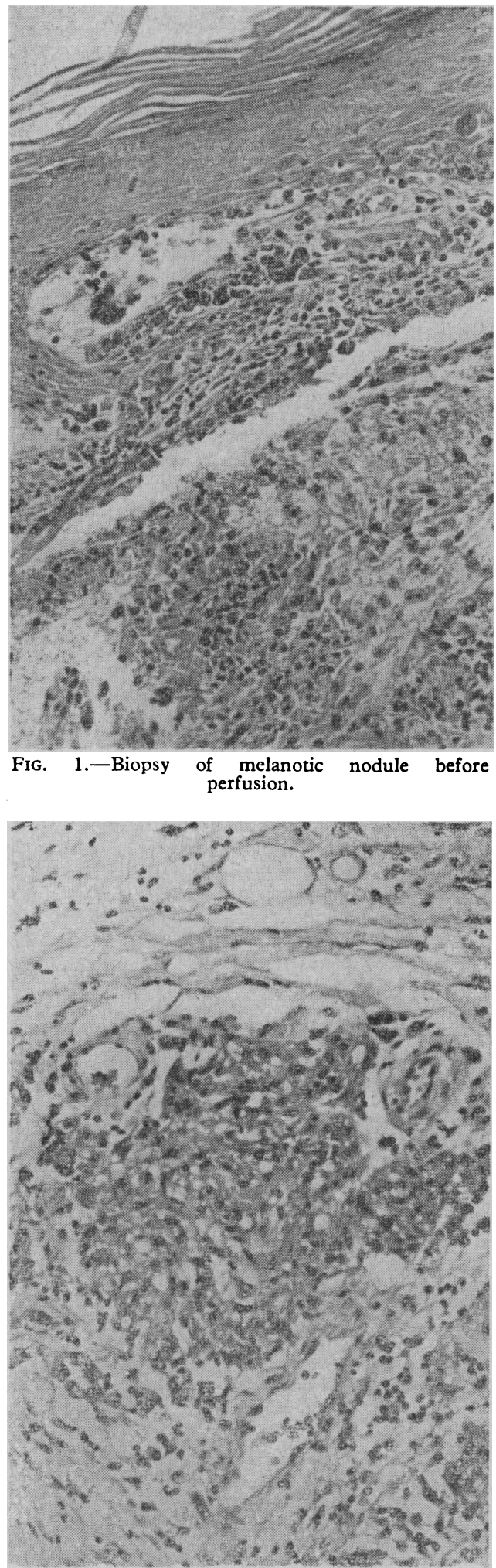

FIG. 2.-Biopsy of same nodule as in Fig. 1 after perfusion. hospital after perfusion without block-dissection was 21 days, and the average stay after perfusion with block-dissection was 44 days. This difference was due to the high incidence of skin necrosis and infection in the groin following block-dissection.

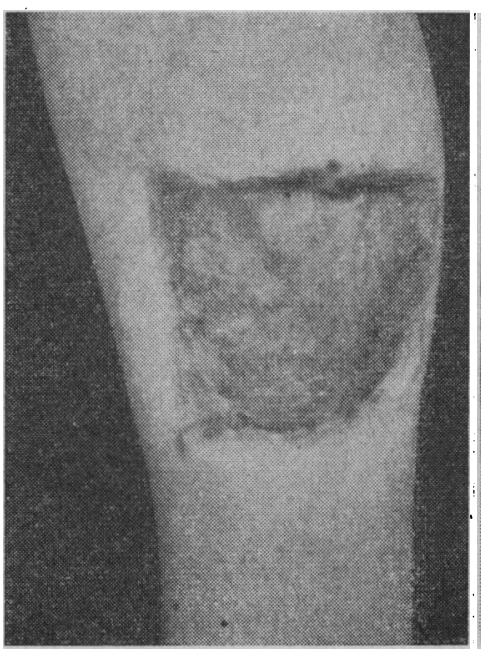

FIG. 3

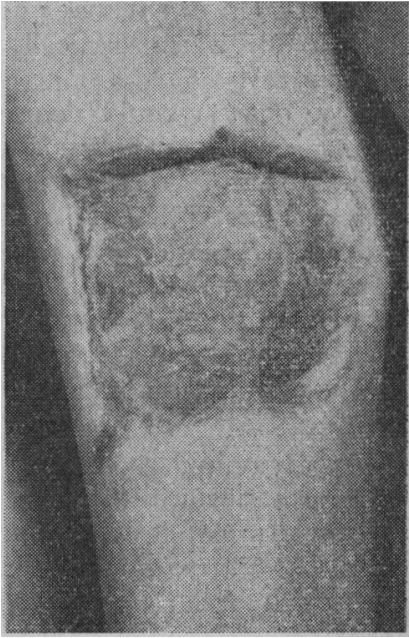

FIG. 4
FIG. 3.-Skin graft on leg showing two recurrent nodules (one in middle of upper edge and the other at lower anterior corner). Fig. 4.-After perfusion - the upper nodule flat and much reduced in size, lower nodale necrotic.

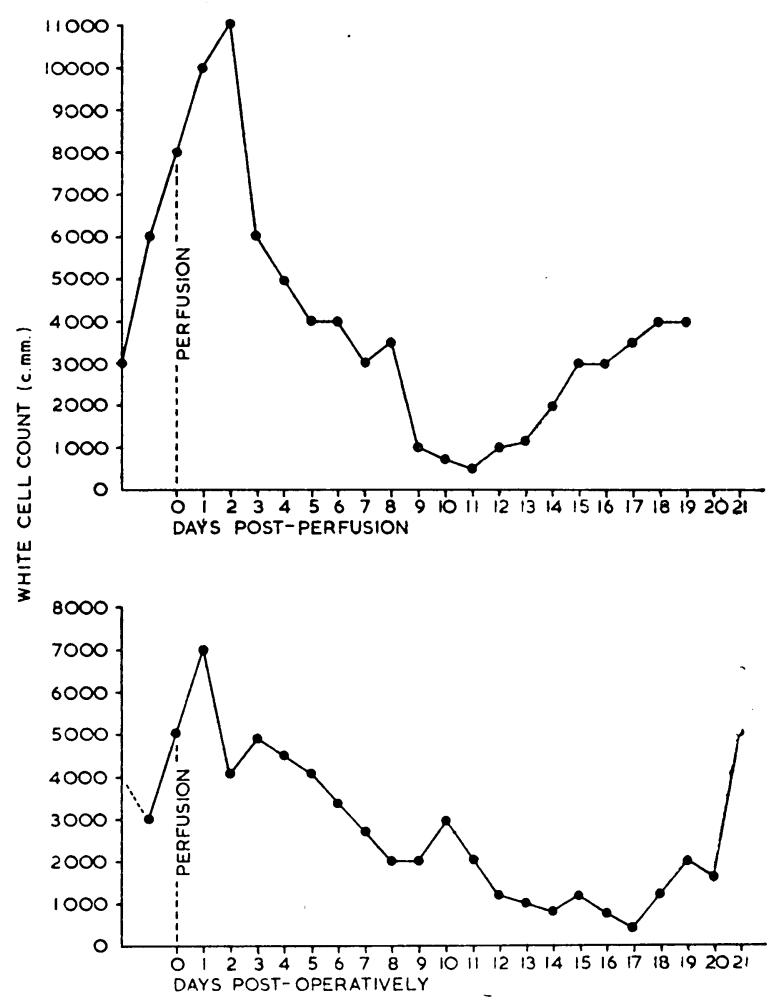

FIG. 5.-White-cell counts of two patients who became leucopenic following perfusion. The patient illustrated in the lower chart had marrow storage and reinfusion.

TABLE V.-Incidence of Lymphoedema Following Perfusion in Relation to Block-dissection of Regional Nodes

\begin{tabular}{|c|c|c|c|c|c|c|c|c|}
\hline \multicolumn{3}{|c|}{$\begin{array}{l}\text { Block-dissection at } \\
\text { Time of Perfusion } \\
\text { (17 Perfusions) }\end{array}$} & \multicolumn{3}{|c|}{$\begin{array}{c}\text { Block-dissection at Some } \\
\text { time before Perfusion } \\
\text { (13 Perfusions) }\end{array}$} & \multicolumn{3}{|c|}{$\begin{array}{c}\text { No } \\
\text { Block-dissection } \\
\text { (3 Perfusions) }\end{array}$} \\
\hline Severe & Moderate & Slight & Severe & Moderate & Slight & Severe & Moderate & $\begin{array}{l}\text { Nil or } \\
\text { Very } \\
\text { Slight }\end{array}$ \\
\hline 3 & 8 & 6 & 3 & 4 & 6 & - & - & 3 \\
\hline
\end{tabular}


Two patients in whom perfusion alone was performed were able to leave hospital eight and nine days respectively after operation.

\section{Discussion}

Melphalan can damage or destroy melanomata in vivo, and this is illustrated clinically and histologically in Figs. 1-4. However, its effect is unpredictable and variable, and Cobb and Walker (1964) could demonstrate no effect of this drug on human malignant melanoma cells in vitro, though in the same experiments Thiotepa (triethylene thiophosphoramide), actinomycin $\mathrm{D}$, and chlorambucil were damaging to the cells in culture. This poses one of the chief problems of cancer chemotherapy-that is, to know which drug to use in any particular tumour or patient; in vitro tests may not be an accurate guide. Creech and Krementz (1964) have used both melphalan and a combination of melphalan and Thiotepa, but it is not clear if one is better than the other.

In obtaining a compound in which a cytotoxic group (nitrogen mustard) is attached to a naturally occurring structure (phenylalanine) it was hoped that uptake by the cell of the cytotoxic moiety would be increased. However, malignant cells are usually deficient in enzyme systems, and it is unlikely that the demand by malignant melanomata for a tyrosine precursot is particularly great. Avidity of the cells for phenylalanine is possibly not the reason for the efficacy of melphalan. The present series is too small for us to say there is any difference in response between amelanotic and melanotic melanoma.

Regional perfusion protects against systemic toxicity of the drug used, and the dose-limiting factor is local tissue damage; Smith et al. (1964) found that the effective therapeutic dose they used for melanoma produced no histological damage of normal tissue other than thickening of the small arteries and arterioles, with an occasional small vessel obliterated. Extensive skin necrosis, of which we have seen one sample, is probably due to widespread occlusion of small vessels rather than to direct toxic damage of the epithelium. There has been no evidence of altered behaviour of the normal melanocytes of the limb.

Apart from damage to normal tissue, one must also consider the possibility of adverse effects of perfusion with cytotoxic drugs on the patient's defence mechanisms. This can occur theoretically in three ways: (1) by releasing more cancer cells into the blood, (2) by damaging local defence mechanism, and (3) by damaging systemic defence mechanism. Limb perfusion reduces the latter to a minimum. Kondo (1964) has found in animals and man that nitrogen mustard reduces the antibody response to a foreign protein auc has had one case in which rapid increase in growth rate of a fibrosarcoma occurred following perfusion with cyclophosphamide. Three patients in the series with fairly advanced disease failing to respond to perfusion died within a few months, but there is no evidence that the treatment hastened death in these patients.

From the experience reported here regional perfusion may prove to be a useful adjuvant to conventional surgery in treatment of early primary disease ; 9 out of 11 patients treated in this way were tree from disease for an average follow-up of 23 months. However, seven of these nine tin $^{-1}$ negative regional nodes and would be expected to do well with conventional treatment alone. Creech and Krementz (1964) have a larger experience and report six out of nine patients free from disease four years after perfusion, but again these numbers are too small to be conclusive.

Recurrent melanomata are unsuitable for surgery other than major amputation, and partial or complete regression can be commonly obtained by perfusion (Creech and Krementz (1964) report that only $11 \%$ failed to respond in their series), but the benefits are usually temporary. Of five patients who showed a good objective response to perfusion four have had some further progression of the disease. Nevertheless the results show four patients alive over three years after regional perfusion for recurrent disease. Methods of selecting the most suitable drug with which to perfuse the tumour are being investigated and may improve the results in the future.

The results shown here for both primary and recurrent disease emphasize the prognostic significance of involvement of the regional nodes. In the early cases a controlled trial of regional perfusion as an adjuvant to surgical excision is required, but for sufficient patients to be obtained a large number of hospitals would have to co-operate.

Lebrun and Smets (1964) reported that regional perfusion was a useful method of palliation in advanced disease. This is not our experience, and the three patients in whom it was tried were not benehted and we are not encouraged to treat advanced disease in this way.

The complications of perfusion have been infrequent; no life or urmb has been lost. Fortner et al. (1964) found that block-dissection of inguinal nodes was associated with a $65 \%$ incidence of delayed wound-healing. In the cases reported here regional perfusion has not increased the incidence of this common complication.

We conclude that regional perfusion of a limb is a safe and effective treatment for malignant melanoma, whereas total body perfusion is unjustified (Irvine et al., 1962). The procedure is technsaily simple for any surgeon with vascular training, and the early results when used as an adjuvant at the time of primary treatment are encouraging. It may also provide useful palliation when local recurrences in the limb are not too extensive.

\section{Summary}

Thirty-three regional limb perfusions in 29 patients with malignant melanoma have been reviewed. The results suggest that this is possibly an effective adjuvant to conventional treatment of the early primary lesion. It also provides an alternative to major amputation in the treatment of recurrent disease but has not proved worth while as a palliative in very advanced disease.

The complication rate is low and there have been no deaths due to operation or drug toxicity.

The early cases in this series were treated in the Surgical Unit of the London Hospital. We would like to acknowledge the substantial support of the London Hospital Research Funds in initiating this project.

\section{REFERENCES}

Ackerman, L. V., and del Regato, J. A. (1954). Cancer : Diagnosis, Treatment and Prognosis, 2nd ed., p. 195. Mosby, St. Louis.

Bergel, F., and Stock, J. A. (1953). A.R. Brit. Emp. Cancer Campgn, 31,6 .

Block, G. E., and Hartwell, S. W. (1961). Ann. Surg. (Suppl.) 154, 74. Charalambidis. P. H., and Patterson, W. B. (1962). Surg. Gynec. Obstet., $115,333$.

Cobb, J. P., and Walker, D. G. (1964). Acta Un. int. Cancr, 20, 206.

Creech, O., and Krementz, E. T. (1964). Acta Amer. med. Ass., 188, 855. 616. Ryan, R. F., and Winblad, J. M. (1958). Ann. Surg., 148, 616.
Fortner, J. G., Booher, R. J., and Pack, G. T. (1964). Sur

Hobbs, J. T., and Edwards, E. A. (1962). Lancet, 2, 273.

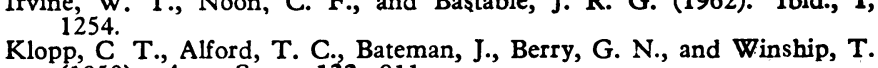
(1950). Ann. Surg., 132, 811.

Kondo, T. (1964). Acta Un. int. Cancr., 20, 194.

Lebrun, J., and Smets, W. (1964). Ibid., 20, 459.

McNeer, G. (1965). Surg. Gynec. Obstet.) 120, 343.

Meyer, H. W., and Gumport, S. L. (1953). Ann. Surg., 138, 643.

Pack, G. T., Gerber, D. M., and Scharnagel, I. M. (1952). Ibid., 136, 905 .

Petersen, N. C.. Bodenham, D. C., and Lloyd, O. C. (1962). Brit. Y. plast. Surg., 15, 49

Sandeman, T. F. (1965) Lancet, 1, 345.

Smith, J. L., Stehlin, J. S. ind Clark, R. L. (1964). Acta Un. int. Cancr., 20, 451 .

Southwick, H. W., Slaughter, D. P., Himkamp, J. F., and Johnson, F. E. (1962). Arch. Surg., 85, 63.

Stehlin, J. S. (1963) Ann. N.Y. Acad. Sci, 100, 128.

Treidman, L., and McNeer, G. (1963). Ibid., 100, 123.

Vogler, W. R., Perdue, G. D., and Wilkins, S. A., jun. (1958). Surg. Gynec. Obstet., 106, 586. 